Supporting Information

\title{
Metastable Rhombohedral Phase Transition of Semiconducting Indium Oxide Controlled by Thermal Atomic Layer Deposition
}

Jung-Hoon Lee ${ }^{a}$, Jiazhen Sheng ${ }^{a}$, Hyesung Anº, TaeHyun Honga, Hyun You Kim ${ }^{b}$, HyunKyung Lee $^{c}$, Jang Hyeon Seokc, Jung Woo Parkc, Jun Hyung Lim*d, and Jin-Seong Park*a

a Division of Materials Science and Engineering, Hanyang University, 222, Wangsimni-ro, Seongdong-gu, Seoul, 04763, Republic of Korea

b Department of Materials Science and Engineering, Chungnam National University, 99 Daehak-ro, Yuseong-gu, Daejeon 34134 Republic of Korea

c Thin Film Material Team, Hansol Chemical, 873, Gwahak-ro, Yongam-ri, Bongdong-eup, Wanju-gun, Jellabuk-do, Republic of Korea

d R\&D Center, Samsung Display, Yongin 17113, Republic of Korea

Corresponding Author

*Email: jsparklime@hanyang.ac.kr (Jin-Seong Park), lanosjh.lim@samsung.com (Jun Hyung Lim) 


\section{Preparation method of Trimethyl[N-(2-methoxyethyl)-2-methylpropan-2-amine]Indium, and its characteristics}

All solvents and reagents were purchased from commercial sources. Toluene and THF (tetrahydrofuran) were purified by distillation after dried with $\mathrm{CaH}_{2}$ or sodium/benzophenone. The nuclear magnetic resonance (NMR) spectra was recorded on a Varian $400 \mathrm{MHz}$. Thermogravimetric analysis (TGA) was carried out on a Mettler Toledo Stare system using a flowing Ar atmosphere. All manipulation was carried out under Ar atmosphere by using standard Schlenk-line techniques.

Synthesis of N-(2-methoxyethyl)-2-methylpropan-2-amine (Ligand)

To solution of 2-methoxyethanamine(49g, $0.42 \mathrm{~mol})$ in THF, was slowly added suspension of $\mathrm{NaH}(15 \mathrm{~g}, 0.63 \mathrm{~mol})$ in $\mathrm{THF}$ at $0^{\circ} \mathrm{C}$, then stirred for $2 \mathrm{~h}$ at ambient-temperature. After then, to reaction mixture, $\mathrm{Mel}(31 \mathrm{ml}, 0.50 \mathrm{~mol})$ was slowly added by using dropping funnel at $0^{\circ} \mathrm{C}$.

The reaction mixture was stirred for overnight. After finished the reaction, the mixture was quenched with isopropyl alcohol, extracted with ether and brine. The organic phase was dried with $\mathrm{MgSO}_{4}$ and filtered. The filtrate solvent was removed under reduced pressure. The crude orange liquid was distilled to give a $\mathrm{N}$-(2-methoxyethyl)-2-methylpropan-2-amine) as colorless liquid. Yield: $21 \mathrm{~g}, 38 \%$.

The NMR peak : ${ }^{1} \mathrm{H}$ NMR $\left(\mathrm{C}_{6} \mathrm{D}_{6}\right): \delta 3.34\left(\mathrm{t}, \mathrm{J}_{\mathrm{CH}}=5.6 \mathrm{~Hz}, 2 \mathrm{H}, \mathrm{OCH}_{2}\right), 3.11\left(\mathrm{~s}, 3 \mathrm{H}, \mathrm{OCH}_{3}\right), 2.62(\mathrm{t}$, $\left.\mathrm{J}_{\mathrm{CH}}=4.8 \mathrm{~Hz}, 2 \mathrm{H}, \mathrm{NCH}_{2}\right), 0.99\left(\mathrm{~s}, 9 \mathrm{H}, \mathrm{NC}\left(\mathrm{CH}_{3}\right)_{3}\right)$ 


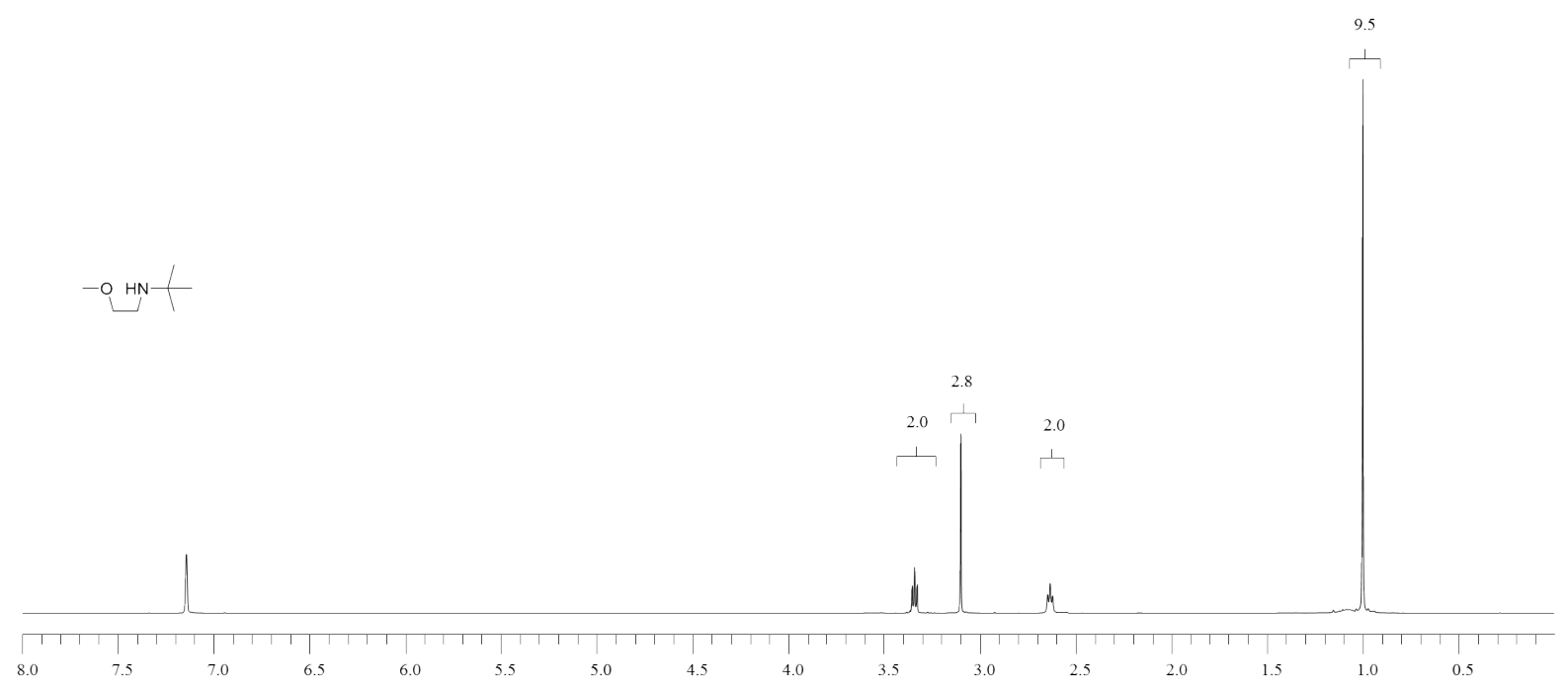

Figure S1. NMR spectra of N-(2-methoxyethyl)-2-methylpropan-2-amine (Ligand)

Synthesis of Trimethyl[N-(2-methoxyethyl)-2-methylpropan-2-amine]Indium

The Trimethylindium(63.9wt\% in ether, $21.7 \mathrm{~g}, 0.14 \mathrm{~mol})$ was dissolved in Toluene. To this solution, N-(2-methoxyethyl)-2-methylpropan-2-amine(ligand) was slowly added by using dropping funnel. The reaction mixture was refluxed for $18 \mathrm{~h}$. After reaction was finished, the solvent removed under reduced pressure. The concentrated crude, brown liquid was distilled $\left(75^{\circ} \mathrm{C}, 0.3\right.$ Torr $)$ in vacuo to give product. Yield: $12.4 \mathrm{~g}, 30 \%$

The NMR peak : ${ }^{1} \mathrm{H} N M R\left(\mathrm{C}_{6} \mathrm{D}_{6}\right): \delta 3.21\left(\mathrm{t}, \mathrm{J}_{\mathrm{CH}}=4.4 \mathrm{~Hz}, 2 \mathrm{H}, \mathrm{OCH}_{2}\right), 2.99\left(\mathrm{~s}, 3 \mathrm{H}, \mathrm{OCH}_{3}\right), 2.45(\mathrm{q}$, $\left.\mathrm{J}_{\mathrm{CH}}=5.2 \mathrm{~Hz}, 2 \mathrm{H}, \mathrm{NCH}_{2}\right), 1.89(\mathrm{br}, \mathrm{s}, 1 \mathrm{H}, \mathrm{NH}), 0.85\left(\mathrm{~s}, 9 \mathrm{H}, \mathrm{NC}\left(\mathrm{CH}_{3}\right)_{3}\right), 0.02\left(\mathrm{~s}, 9 \mathrm{H}, \ln \left(\mathrm{CH}_{3}\right)_{3}\right)$, 


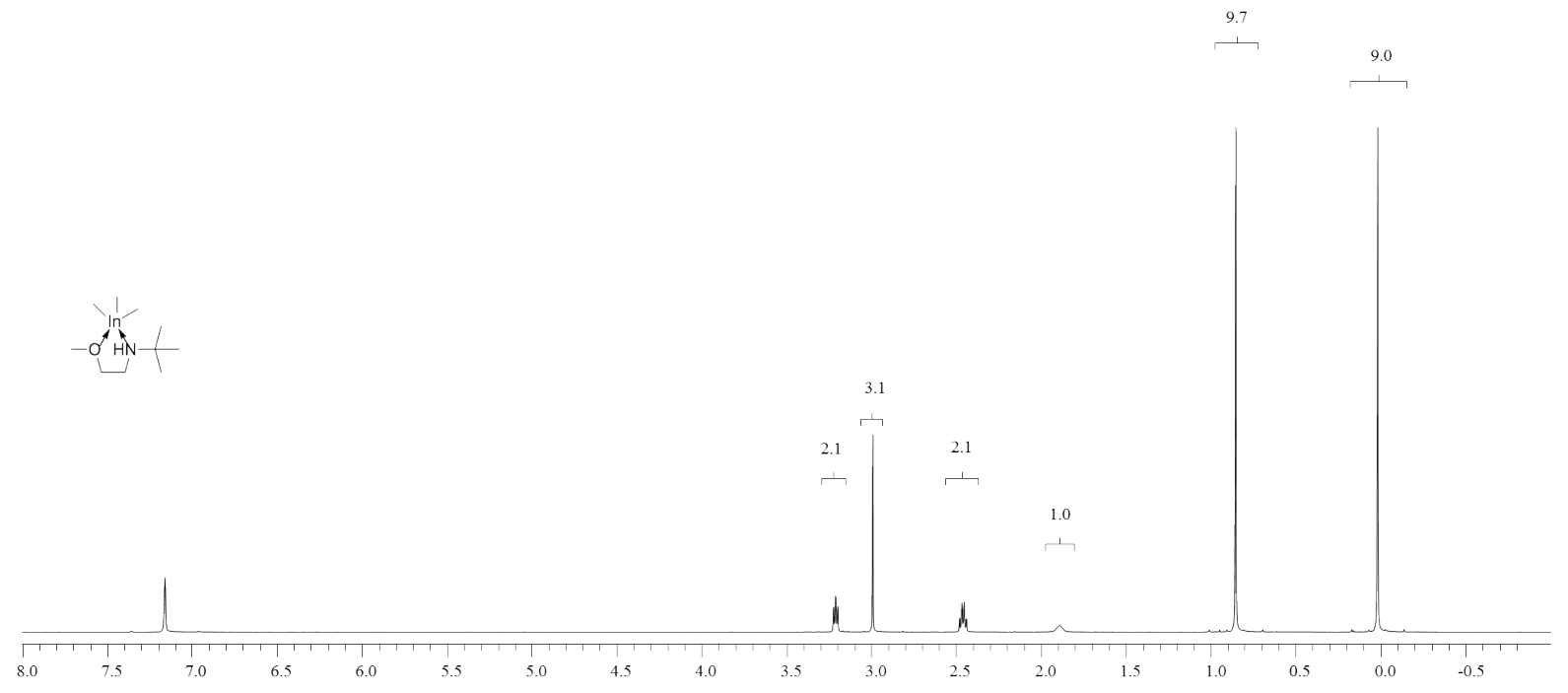

Figure S2. NMR spectra of Trimethyl[N-(2-methoxyethyl)-2-methylpropan-2-amine]Indium 


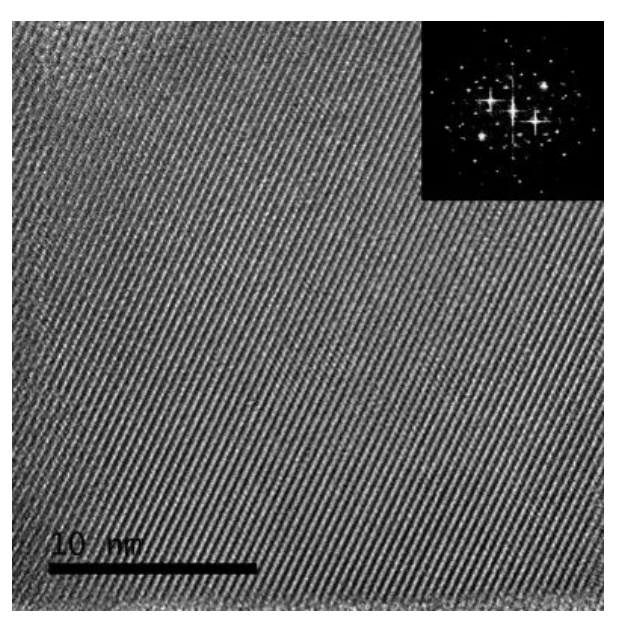

Figure S3. clear long-range order (00/) plane of cubic structured $\ln _{2} \mathrm{O}_{3}$ films deposited at $200^{\circ} \mathrm{C}$ 
(a)

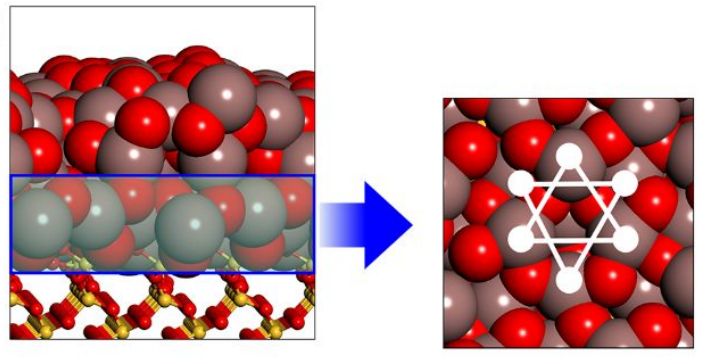

(b)

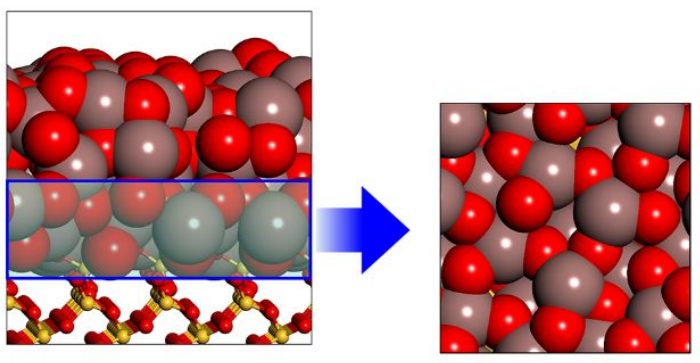

Figure S4. Atomic arrangement of a sliced $\ln _{2} \mathrm{O}_{3}$ layer of (a) rhombohedral$\ln _{36} \mathrm{O}_{54} / \mathrm{In}_{32} \mathrm{O}_{48} / \mathrm{SiO}_{2}(001)$ and (b) cubic- $\operatorname{In}_{36} \mathrm{O}_{54} / \mathrm{In}_{32} \mathrm{O}_{48} / \mathrm{SiO}_{2}(001)$. A typical local atomic arrangement of rhombohendral- $\mathrm{In}_{2} \mathrm{O}_{3}$ was appeared in rhombohedral$\mathrm{In}_{36} \mathrm{O}_{54} / \mathrm{In}_{32} \mathrm{O}_{48} / \mathrm{SiO}_{2}(001)$ (white highlighted triangles). 


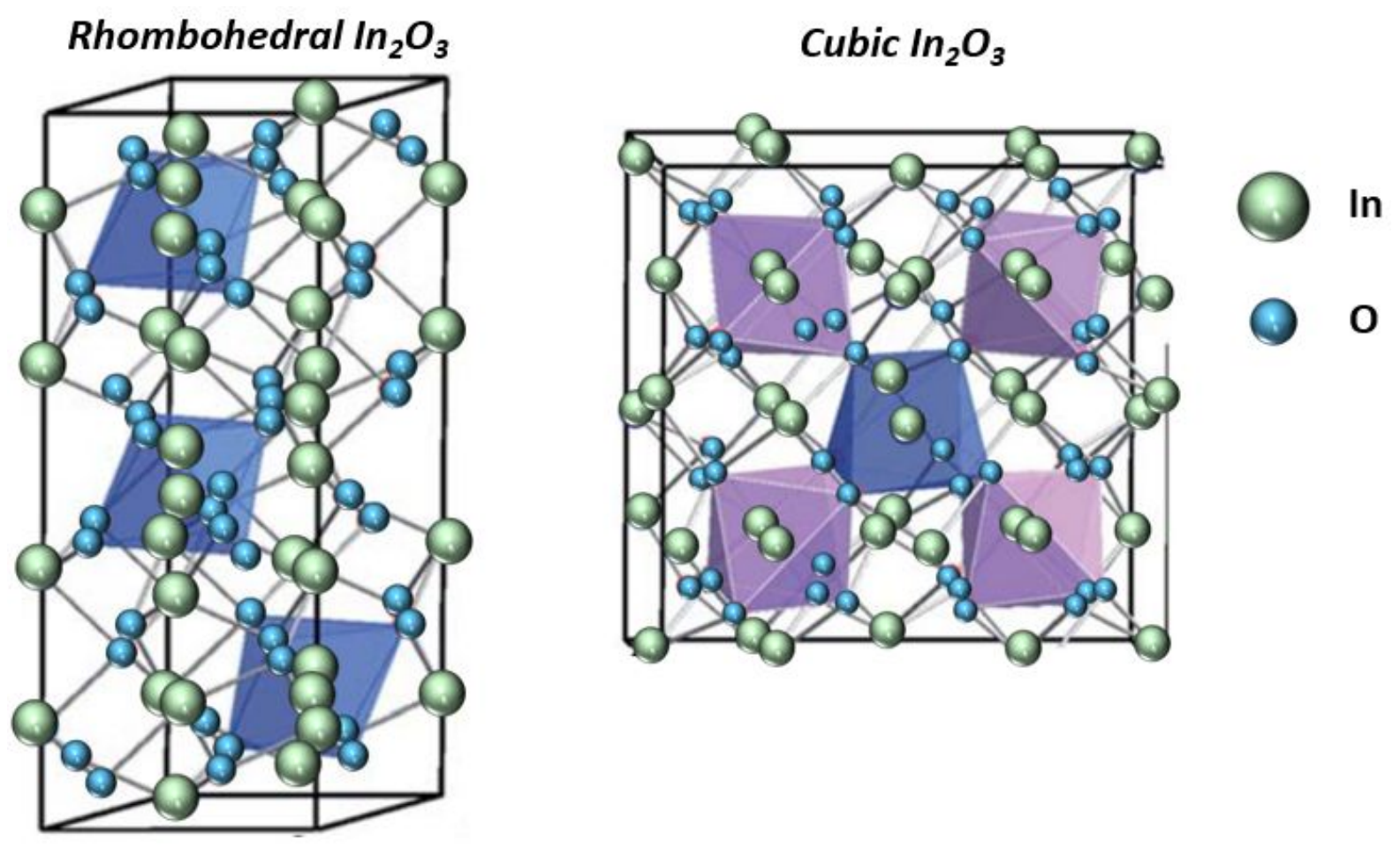

Figure S5. bulk rhombohedral (left) and cubic (right)- $\ln _{2} \mathrm{O}_{3}$ structure 


\begin{tabular}{cccc} 
& $\begin{array}{c}\text { Bulk } \\
\text { rhombohedral } \ln _{2} \mathrm{O}_{3}\end{array}$ & $\begin{array}{c}\text { Bulk } \\
\text { cubic } \ln _{2} \mathrm{O}_{3}\end{array}$ & $\begin{array}{c}\text { rhombohedral- } \\
\ln _{36} \mathrm{O}_{54} / \ln _{32} \mathrm{O}_{48} / \mathrm{SiO}_{2}(001)\end{array}$ \\
\hline $\mathrm{E}_{\mathrm{vac}}[\mathrm{V}]$ & -2.0 & -1.8 & -1.5 \\
\hline
\end{tabular}

Table S1. DFT-calculated oxygen vacancy formation energy of $\ln _{2} \mathrm{O}_{3}$. 


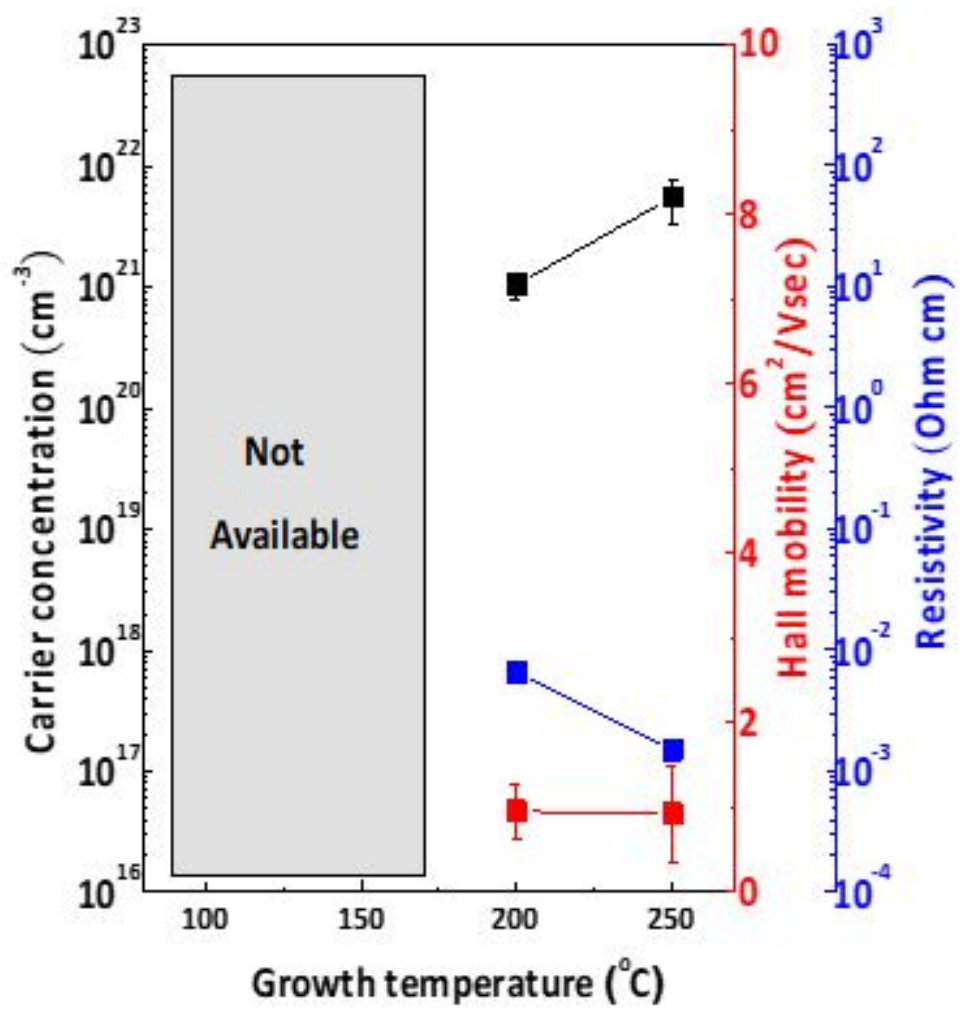

Figure S6. Carrier concentration, Hall mobility, and resistivity of $\ln _{2} \mathrm{O}_{3}$ films. For the deposition temperatures $100^{\circ} \mathrm{C}$ and $150^{\circ} \mathrm{C}$, carrier concentration and resistivity could not be measured due to extremely high resistivity due to the limitation of measurement. The measured resistivity of devices deposited at $200{ }^{\circ} \mathrm{C}$ and $250{ }^{\circ} \mathrm{C}$ is $1.05 \times 10^{21} \mathrm{~cm}^{-3}$ and $5.53 \times 10^{21} \mathrm{~cm}^{-3}$, respectively, as increasing temperature, carrier concentration increased, although the Hall mobility showed no significant change. 